Check for updates

Cite this: RSC Adv., 2018, 8, 17806

Received 7th April 2018

Accepted 3rd May 2018

DOI: $10.1039 / \mathrm{c} 8 \mathrm{ra02982b}$

rsc.li/rsc-advances

\title{
Practical, mild and efficient electrophilic bromination of phenols by a new I(III)-based

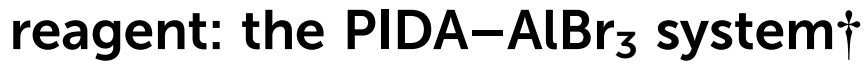

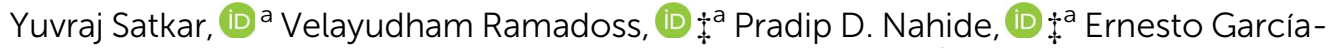
Medina, ${ }^{a}$ Kevin A. Juárez-Ornelas, ${ }^{a}$ Angel J. Alonso-Castro, ${ }^{\text {b }}$ Ruben Chávez-Rivera, ${ }^{C}$ J. Oscar C. Jiménez-Halla (iD *a and César R. Solorio-Alvarado iD *a

A practical electrophilic bromination procedure for phenols and phenol-ethers was developed under efficient and very mild reaction conditions. A broad scope of arenes was investigated, including the benzimidazole and carbazole core as well as analgesics such as naproxen and paracetamol. The new I(III)-based brominating reagent $\mathrm{PhIOAcBr}$ is operationally easy to prepare by mixing PIDA and $\mathrm{AlBr}_{3}$. Our DFT calculations suggest that this is likely the brominating active species, which is prepared in situ or isolated after centrifugation. Its stability at $4{ }^{\circ} \mathrm{C}$ after preparation was confirmed over a period of one month and no significant loss of its reactivity was observed. Additionally, the gram-scale bromination of 2-naphthol proceeds with excellent yields. Even for sterically hindered substrates, a moderately good reactivity is observed.

\section{Introduction}

Aryl bromides are compounds of great importance in organic chemistry. ${ }^{1}$ They appear or are frequently used in materials science, ${ }^{2}$ agrochemicals, ${ }^{3}$ natural compounds ${ }^{4}$ and pharmaceuticals ${ }^{5}$ (Fig. 1). Moreover, they constitute important building blocks for $\mathrm{C}-\mathrm{C}$ bond formation, in the transition-metal-free procedures $^{6}$ or metal-catalyzed Suzuki, ${ }^{7}$ Stille $^{\mathbf{8}, 37}$ and Negishi ${ }^{9}$ cross-coupling reactions as well as the Mizoroki-Heck ${ }^{\mathbf{1 0}}$ olefination and the Sonogashira ${ }^{11}$ alkynylation.

To date, several procedures for the bromination of arenes have been reported. Among the most representative of these, metal-catalyzed bromination reactions using $\mathrm{Ru},{ }^{12} \mathrm{Rh},{ }^{13} \mathrm{~V},{ }^{14} \mathrm{Cu},{ }^{15}$ $\mathrm{Pd}^{16}$ or $\mathrm{Au}^{17}$ are excellent examples. On the other hand, $\mathrm{Br}_{2}$ - and NBS-based brominating procedures are broadly used in the presence of organocatalysts, ${ }^{18}$ ionic liquids,${ }^{19} \mathrm{TMSCl}^{, 20}$ supercritical $\mathrm{CO}_{2}$ (ref. 21) or $\mathrm{Fe}_{2} \mathrm{O}_{3}$-zeolite ${ }^{22}$ as additives or reaction media. Regarding the reagent-economy procedures, the oxidation of different bromide salts is a widely exploited tool. Thus,

${ }^{a}$ Universidad de Guanajuato, Departamento de Química, División de Ciencias Naturales y Exactas, Campus Guanajuato, Cerro de la Venada $S / N, 36040$, Guanajuato, Gto., México.E-mail: csolorio@ugto.mx; jjimenez@ugto.mx

${ }^{b}$ Universidad de Guanajuato, Departamento de Farmacia, División de Ciencias Naturales y Exactas, Campus Guanajuato, Noria alta S/N, 36050, Guanajuato, Gto., México

'Universidad Michoacana de San Nicolás de Hidalgo, Facultad de Químico Farmacobiología, Tzintzuntzan 173, col. Matamoros, Morelia, Mich., México

† Electronic supplementary information (ESI) available. See DOI: 10.1039/c8ra02982b

\$ These two authors contributed equally to the paper. a range of different oxidant systems, such as $\mathrm{HBr}-$ Selectfluor ${ }^{23},{ }^{23}$ $\mathrm{HBr}-\mathrm{H}_{2} \mathrm{O}_{2}{ }^{24} \mathrm{HBr}-\mathrm{DMSO}^{25}$ or $\mathrm{KBr}^{-\mathrm{I}_{2} \mathrm{O}_{5}}$ (ref. 26) have been successfully utilized. Finally, in the context of this work, bromide salt oxidation by I(III) reagents is a particularly elegant and useful bromination strategy. In this regard, the work of Braddock, ${ }^{27}$ $Z$ hou $^{28}$ and Evans ${ }^{29}$ should be emphasized (Scheme 1). Herein we describe an economical procedure developed for the efficient electrophilic bromination of the phenolic core, whereby an I(III) reagent oxidizes the bromine atoms of $\mathrm{AlBr}_{3}$. A number of representative advantages of this strategy over those previously published are highlighted, such as its easy handling, fast in situ formation of the brominating reagent and mild, non-toxic as well as operationally simple procedure.

\section{Results}

Recently, we described an efficient procedure for the chlorination of electron-rich arenes using the PIFA-AlCl ${ }_{3}$ system (PIFA = $\left.\mathrm{PhI}(\mathrm{OTFA})_{2}\right){ }^{30}$ These results inspired us to extend our oxidative halogenation strategy to the bromination of arenes. In this way we decided to test the hypothesis by initially mixing PIFA and $\mathrm{AlBr}_{3}$, in order to effect the bromination of 2-naphthol. Our optimization results are summarized in Table 1.

We started the optimization by using 0.5 and 1.0 equiv. of PIFA and 2.4 equivalents of aluminium tribromide in acetonitrile at room temperature. As expected, we found that the reaction gave 1-bromo-2-naphthol in yields of $28 \%$ and $81 \%$, respectively (entries 1 and 2). These experiments validated our hypothesis, and in principle, we could extend our previously developed oxidative halogenation procedure to the bromination 

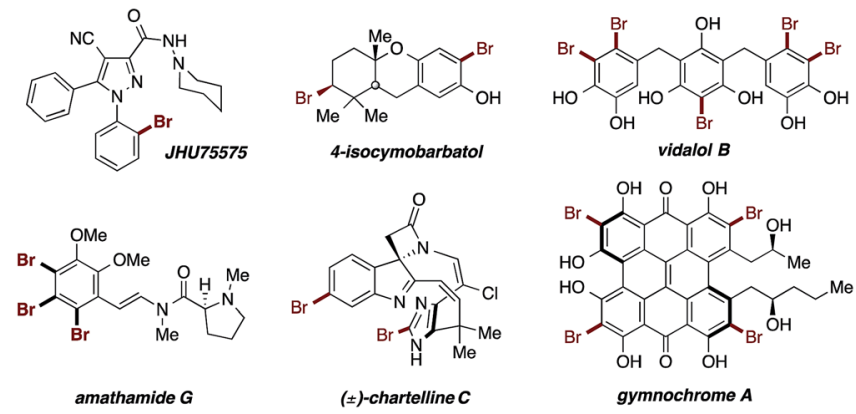

Fig. 1 Examples highlighting the aryl bromide core relevance.

of arenes. It was also evident that at least a stoichiometric amount of the I(III) reagent is necessary as oxidant for completion of the reaction. Then, maintaining the aluminium tribromide amount at 2.4 equivalents and keeping acetonitrile as solvent, one equivalent of PIFA at $40{ }^{\circ} \mathrm{C}$ was tested (entry 3), leading to a decreased yield (65\%). By using 1.5 equivalents of PIFA we obtained a yield of $84 \%$ (entry 4 ), which is slightly higher than entry 2 . The use of two equivalents of PIFA gave a lower yield, corresponding to $78 \%$ (entry 5). When the solvent was changed to dichloromethane, a very complex reaction mixture was observed (entry 6). At this point, entry 2 represented a promising result. However, we realized that while PIFA and PIDA ((diacetoxyiodo)benzene) are structurally similar reagents, commercial PIDA is $c a$. one-third the price of PIFA. Thus, we tested the conditions used in entry 2 with PIDA as oxidant. Gratifyingly, this reaction provided an excellent 93\% yield (entry 7). The use of 1, 1.5 and 2 equivalents of aluminium tribromide (entries 8-10) did not lead to completion of the reaction presumably due to lower bromine concentration compared to entry 7 and gave moderate to poor yields (ca. $44 \%$ to $73 \%$ ). We determined that 2.4 equivalents was thus the optimal amount of aluminium tribromide. Further attempts to optimize PIDA, solvent or temperature (entries 11-15), gave lower yields or complex reaction mixtures. Finally, control experiments, performed by testing only aluminium tribromide, did not produce any observable reaction. This set of experiments suggested that entry 7 is the best choice of conditions for the oxidative halogenation of arenes. To the best of our knowledge, this is the first report describing an oxidation of the

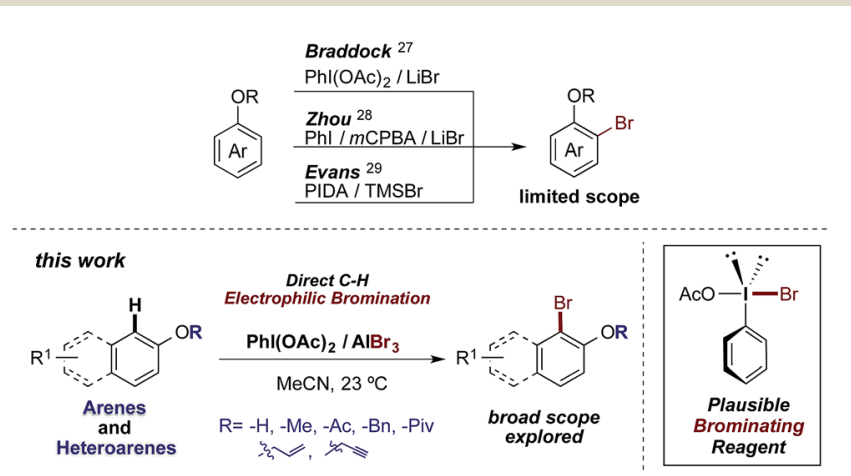

Scheme 1 I(III)-based bromination methods. bromine atoms of $\mathrm{AlBr}_{3}$ to a " $\mathrm{Br}^{+}$" equivalent using an I(III) reagent. Additionally, the change of PIFA (6 USD per $g$ ) to PIDA as the oxidant makes the reaction a synthetically and economically attractive procedure, since the starting materials are cheap: $\operatorname{AlBr}_{3}$ (2 USD per g) and PIDA (1.9 USD per g).

With the optimal conditions in hand, we proceeded to test the scope and limitations of our oxidative bromination protocol (Scheme 2).

A range of electron-rich and electron-poor phenolic substrates was tested, as well as some of their methyl-ether derivatives. Thus, 2-naphthol was brominated in $93 \%$ yield to obtain 1, and this reaction also gave an excellent $91 \%$ yield when performed on a gram-scale. This experiment demonstrated the scalability and efficiency of our procedure. 2Methoxynaphthalene was also brominated in $88 \%$ yield to afford 2. In addition, electron-poor naphthol derivatives containing bromine and chlorine were successfully brominated (3 to 10). The bromination of 4-bromo-1-naphthol and its methylether led to 3 and 4 in $86 \%$ and $92 \%$ yields, respectively. Starting from 1-bromo-2-naphthol or 6-bromo-2-naphthol, 94\% and 96\% yields were obtained for 5 and 7, respectively. Their corresponding methyl-ethers furnished the desired brominated derivatives in $86 \%$ to $88 \%$ yields for compounds 6 and 8 , respectively. Also the bromination of 1-chloro-2-naphthol synthesized by our procedure, ${ }^{30}$ and its methyl-ether, proceeded in $90 \%$ and $88 \%$ yields, respectively. The monobromination of the electron-rich 7-methoxy-2-naphthol yielded 11 in $54 \%$ and the corresponding methyl-ether was

Table 1 Optimization of the bromination of 2-naphthol using the I(III)$\mathrm{AlBr}_{3}$ system

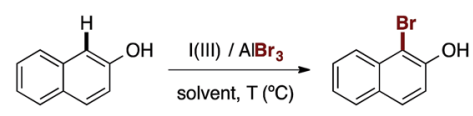

\begin{tabular}{llllll} 
Entry & I(III) (equiv.) & AlBr $_{3}$ equiv. & Solvent & Temp. $\left({ }^{\circ} \mathrm{C}\right)$ & Yield $^{a}(\%)$ \\
\hline 1 & PIFA (0.5) & 2.4 & MeCN & 23 & 28 \\
2 & PIFA (1.0) & 2.4 & MeCN & 23 & 81 \\
3 & PIFA (1.0) & 2.4 & MeCN & 40 & 65 \\
4 & PIFA (1.5) & 2.4 & MeCN & 23 & 84 \\
5 & PIFA (2.0) & 2.4 & MeCN & 23 & 78 \\
6 & PIFA (1.0) & 2.4 & DCM & 23 & c.r.m. \\
7 & PIDA (1.2) & 2.4 & MeCN & 23 & 93 \\
8 & PIDA (1.0) & 1.0 & MeCN & 23 & 32 \\
9 & PIDA (1.0) & 1.5 & MeCN & 23 & 44 \\
10 & PIDA (1.0) & 2.0 & MeCN & 23 & 73 \\
11 & PIDA (1.5) & 2.4 & MeCN & 23 & 70 \\
12 & PIDA (1.0) & 2.4 & MeCN & 40 & 72 \\
13 & PIDA (1.0) & 2.4 & DCM & 23 & c.r.m. \\
14 & PIDA (1.0) & 2.4 & DCE & 23 & c.r.m. \\
15 & PIDA (1.0) & 2.4 & THF & 23 & 57 \\
16 & - & 1.0 & MeCN & 23 & n.r. \\
17 & - & 2.0 & MeCN & 23 & n.r.
\end{tabular}

${ }^{a}$ All reactions were carried out without the use of inert atmosphere. Isolated yields are described. n.r. $=$ no reaction observed. PIFA $=$ $\mathrm{PhI}(\mathrm{OTFA})_{2}$ or [bis(trifluoroacetoxy)iodo]benzene. $\mathrm{PIDA}=\mathrm{PhI}(\mathrm{OAc})_{2}$ or (diacetoxyiodo)ben-zene. c.m.r. = complex reaction mixture. 


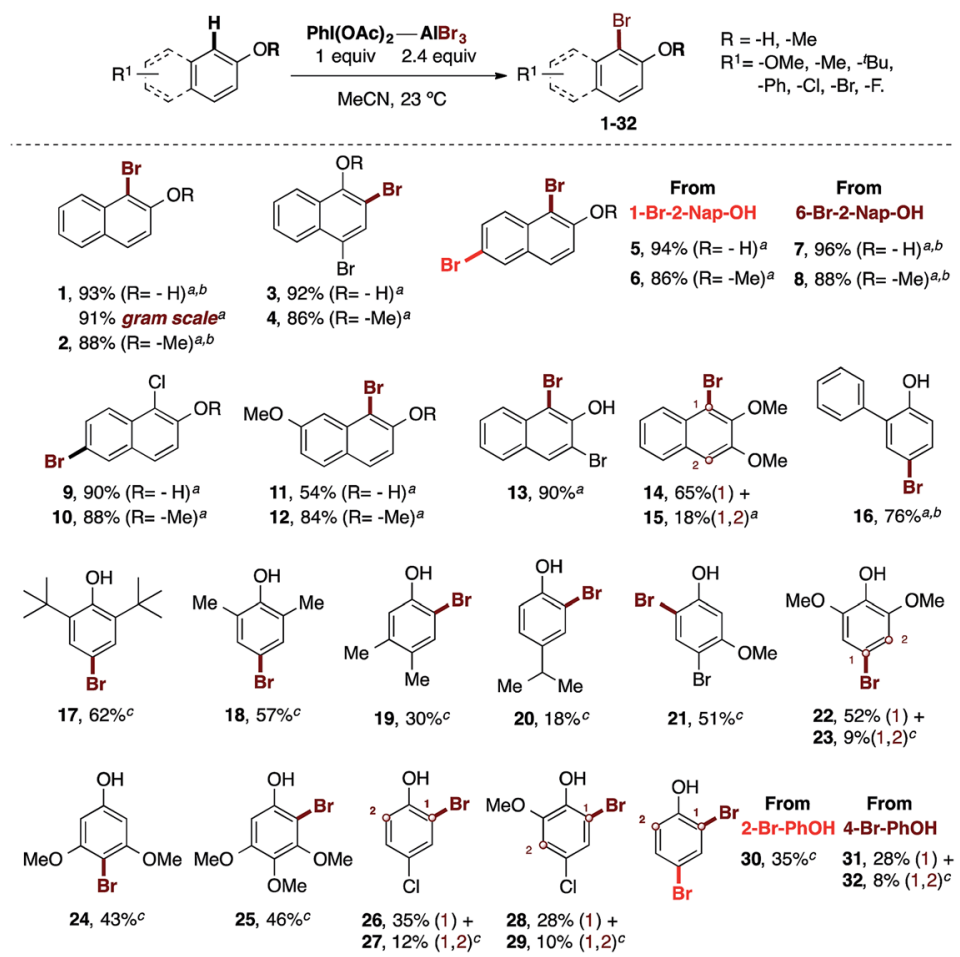

Scheme 2 Scope of the oxidative bromination at the phenol core using the PIDA-AlBr 3 system. Isolated yields are described. The reactions were carried out in the presence of 1.2 equiv. of an I(III) source as oxidant, 2.4 equiv. of $\mathrm{AlBr}_{3}$ in $\mathrm{MeCN}$ at $23^{\circ} \mathrm{C}$, open flask and without inert atmosphere. ${ }^{a}$ Reactions were carried out using PIDA as oxidant (general procedure A, see ESI + ). ${ }^{\mathrm{b}}$ Reactions were carried out using PIFA as oxidant (general procedure B, see ESI†). ${ }^{C}$ Reactions were carried out using the general procedure C (see ESI $\dagger$ ). The newly-formed carbon-bromine bond is highlighted in red.

monobrominated in $84 \%$ yield to afford 12 . The 3-bromo-2naphthol was brominated in excellent $90 \%$ yield to get 13 . In the same way the 2,3-dimethoxynaphthalene was brominated to afford a separable mixture of $\mathbf{1 4}$ and $\mathbf{1 5}$ in $65 \%$ and $18 \%$ respectively. This set of experiments highlight the efficacy of our protocol applied to the bromination of naphthols. The further scope of the reaction was tested with different mono-annular phenols. Thereby, electron-rich phenols containing various aryl or alkyl groups such as phenyl, methyl, iso-propyl or tertbutyl, were successfully brominated. Compound 16 containing a phenyl ring was obtained in $76 \%$ yield. The bulky 2,6 -di-tertbutylphenol provided 17 in $62 \%$ yield. We observed that the more hindered the substituents of the phenolic core are, the lower the yield is. Additionally, the typical para regioselectivity was obtained. In comparison, the less bulky but also less electron-rich 2,6-dimethylphenol furnished 18 in 57\% yield. The weakly electron-donating 3,4-dimethylphenol produced the ortho-brominated derivative 19 in $30 \%$ yield. This example shows a dramatic decrease in yield, which clearly indicates that the reaction at the para position is chemically preferred and the steric hindrance in the proximity of the hydroxyl group also affects our procedure. In this regard, the bromination of 4-isopropoxyphenol was achieved in $18 \%$ yield to obtain 20 , confirming our hypothesis. Thus, we identified that bulky substituents at the para position with respect to the hydroxyl group may also affect the yield. On the other hand, the presence of one, two or three strongly electron-donating methoxy groups afford moderate yields of $43 \%$ to $52 \%$ for 21 to 25 . Finally, to complete this scope, a number of electron-deficient phenols were examined. Accordingly, 2-bromophenol was brominated in $35 \%$ yield to provide 30 . The bromination of 4 -bromophenol provided 31 in $28 \%$ yield and the bis-brominated derivative 32 in $8 \%$ yield as a separable mixture of products from a complex reaction. Similarly low yields were observed for chloro derivative. This way, 4-chlorophenol gave 26 and 27 in $35 \%$ and $12 \%$ of yield. Also the bromination of 4-chloro-2-methoxynaphthol provide 28 and 29 in $28 \%$ and $10 \%$ yields, respectively.

These results clearly delineate the scope and limitations of our protocol. The procedure is excellent for naphthols, moderately good for electron-rich mono-annular phenols, but struggles with bulky para-substituted phenols as well as those electron-poor phenols.

However, it is important to highlight the following advantages of our protocol: (1) the reagent-economy, (2) the operational ease of handling, (3) the absence of the need for an inert atmosphere, (4) the absence of the need for reagent activation, as required in the known NBS-based procedures, and (5) excellent yields are shown in general for naphthols.

Subsequently, we tested the scope of this procedure with further compounds to identify the tolerance of the reaction to different functional groups and heterocycles, which could negatively impact our brominating procedure at the naphthol moiety (Scheme 3). 

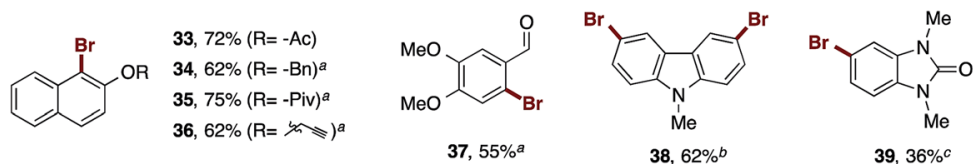

$38,62 \%$

$39,36 \%$
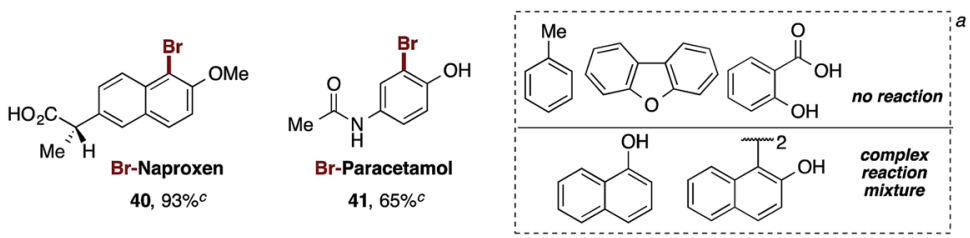

Scheme 3 Scope of the functional groups and heterocycles used in the bromination reaction by the PIDA-AIBr 3 system. Isolated yields are shown. ${ }^{\mathrm{a}}$ Reactions were carried out in the presence of 1.2 equiv. of PIDA and 2.4 equiv. of $\mathrm{AlBr}_{3}$ at $80{ }^{\circ} \mathrm{C}$. ${ }^{\mathrm{b}} \mathrm{Reactions}$ were carried out in the presence of 2.4 equiv. of PIDA and 4.8 equiv. of $\mathrm{AlBr}_{3}$ at $80^{\circ} \mathrm{C}$. ${ }^{\mathrm{C}}$ Reactions were carried out in the presence of 1.2 equiv. of PIDA and 2.4 equiv. of $\mathrm{AlBr}_{3}$ at $23{ }^{\circ} \mathrm{C}$.

In this regard, the functionalization of 2-naphthol at the oxygen with the benzyl and propargyl groups was explored, in addition to acyls of assorted sizes. Thereby, the acetyl derivative yielded the corresponding brominated naphthol 33 in $72 \%$ yield. The presence of a benzyl group allowed the bromination reaction to obtain 34 to proceed in $62 \%$ yield. In this case, the amounts of the oxidant and bromine source had to be doubled, and heating to $80{ }^{\circ} \mathrm{C}$ was necessary for complete consumption of the starting material. The pivaloyl and propargyl naphthol derivatives afforded the desired compounds 35 and 36 in $75 \%$ and $62 \%$ yields, respectively, under the previous conditions. ${ }^{31}$

These tests demonstrate the excellent reactivity of our reagent, which provided good yields for sterically hindered naphthols even in the presence of bulky groups such as pivaloyl. The increased amounts of PIDA and $\mathrm{AlBr}_{3}$, and the increase of the temperature to $80{ }^{\circ} \mathrm{C}$, still represent mild reaction conditions, and maintain the high reactivity of our brominating reagent. At this point, we tested the reaction with mono-annular phenols bearing other functional groups. Thus, the formyl group was tolerated in the phenolic core, furnishing product 37 in $55 \%$ yield. The carboxylic acid and the methyl derivatives failed under our bromination conditions. Likewise, heterocycles such as $N$-methylcarbazole, and $N, N^{\prime}$-dimethylbenzimidazolone were brominated in $62 \%$ and $36 \%$ to yield 38 and 39 respectively. The dibenzofuran did not react. Finally, we sought to directly brominate some common pharmacologically active analgesics as their sodium salts. The sodium salt of naproxen gave rise to its corresponding bromo-derivative $\mathbf{4 0}$ in excellent yield (93\%), while the sodium salt paracetamol was brominated to provide $\mathbf{4 1}$ in $65 \%$ yield. Examples such as 1-naphthol and the 2-naphthol dimer provided complex reaction mixtures.

During the exploration of the functional group scope of this reaction, we observed an interesting reactivity of the allyl and ester functionalities (eqn (1) and (2)).

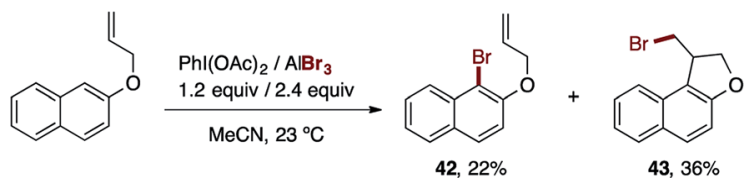

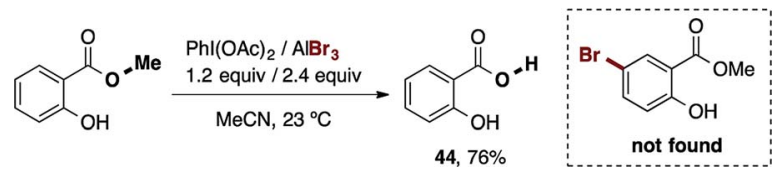

Specifically, the bromination of 2-(allyloxy)naphthalene (eqn (1)) afforded two compounds, the expected brominated compound 42 (22\% yield) and the naphthofuran 43 (36\% yield). The former product is the result of the cationic- $\pi$ bromocyclization induced by our reagent. This is a very important feature which provides the possibility of applying our procedure in polyene bromocyclizations. ${ }^{32}$ While the obtained yield for $\mathbf{4 3}$ was not particularly high, the optimization of this cyclization reaction is a possibility for future work. On the other hand (eqn (2)), when we attempted the bromination reaction of the salicylic acid methyl-ester, the corresponding carboxylic acid $\mathbf{4 4}$ was obtained in $76 \%$ yield. This reaction represents a novel and mild procedure to transform the ester into carboxylic acids via halolysis.

We then carried out attempts to synthesize and characterize a plausible active brominating species from this reaction. ${ }^{33}$ Thereby, PIDA and $\operatorname{AlBr}_{3}(1: 2)$ were mixed and stirred for 30 minutes at room temperature. After centrifugation and solvent concentration, we obtained a yellow-orange solid with a strong smell of bromine. Several attempts to obtain tractable ${ }^{1} \mathrm{H}$ and ${ }^{13} \mathrm{C}$ NMR spectra showed only decomposition, as judged from the complexity of the observed NMR signals. This observation is presumably a result of decomposition due to thermal

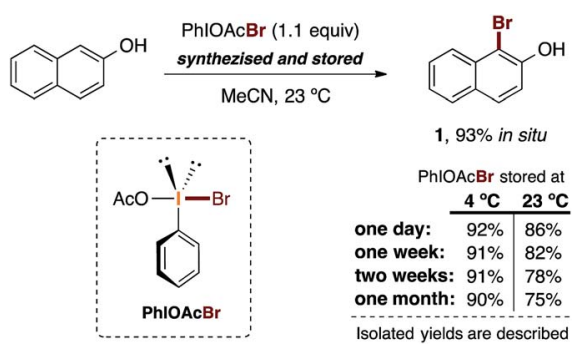

Scheme 4 Experimental study on the thermal stability and reactivity of the proposed active species PhlOAcBr for our developed bromination procedure. 


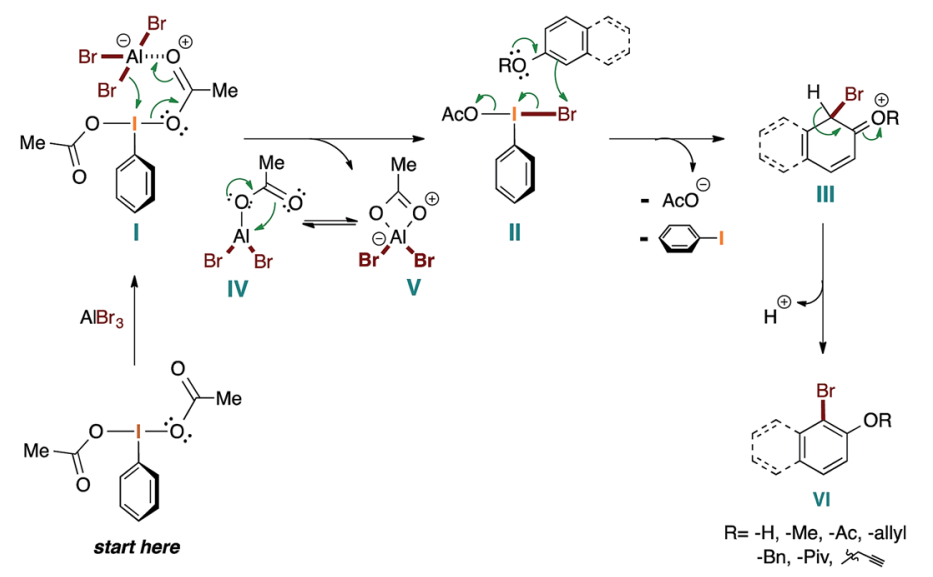

Scheme 5 Mechanic proposal for the electrophilic bromination mediated by the PIDA-AlBr 3 system.

sensitivity. Nevertheless, the evidence obtained while isolating this new solid and its organoleptic characteristics suggested to us that this is presumably the active species in the reaction. With this hypothesis in mind, we decided to test this solid as the plausible brominating species (PhIOAcBr) in the bromination of 2-naphthol. Also, to evaluate the possible thermal sensitivity of the reagent, we carried out the bromination reaction over the period of one month by comparing two storage temperatures: $23{ }^{\circ} \mathrm{C}$ and $4{ }^{\circ} \mathrm{C}$ (Scheme 4).

To our delight, using 1.1 equiv. of the presumed active brominating species (PhIOAcBr) in acetonitrile at $23{ }^{\circ} \mathrm{C}$ provided an excellent yield (92\%) of $\mathbf{1}$. This reaction was carried out the day after the synthesis of the reagent, which was stored at $4{ }^{\circ} \mathrm{C}$ before use. When the reaction was attempted with a reagent stored at $23{ }^{\circ} \mathrm{C}$ for one day, we obtained a lower yield $(86 \%)$. In general, bromination reactions with reagents stored at $4{ }^{\circ} \mathrm{C}$ gave essentially the same high yields ( $91 \%$ to $90 \%$ ) even after one month of storage. In the reactions carried out with the reagent stored at $23{ }^{\circ} \mathrm{C}$, notably diminished but still encouraging yields were observed ( $86 \%$ to $75 \%$ ) over a period of one month.

These reactions potentially implicate PhIOAcBr as the plausible brominating active species, which can be synthesized in situ or by mixing PIDA with $\mathrm{AlBr}_{3}$, followed by centrifugation and isolation. Moreover, theoretical calculations were carried out to provide preliminary support for the identity of the active species. The enthalpy and Gibbs free energy of the reaction between PIDA and $\mathrm{AlBr}_{3}$ in acetonitrile at $23{ }^{\circ} \mathrm{C}$ were calculated at the (smd:acetonitrile)M08-hx/(LANL08d, G-311G*) level ${ }^{34}$ and suggest the favorable formation of PhIOAcBr (eqn (3)).

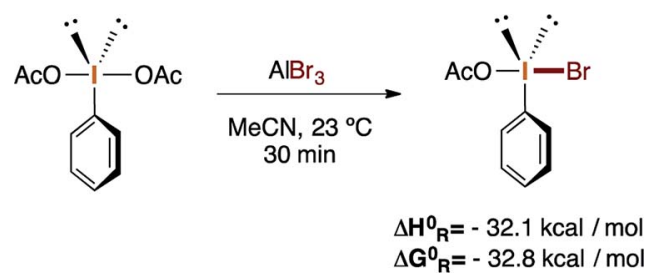

In light of these results, additional calculations are currently underway in our group to establish a plausible reaction mechanism for this novel procedure. Meanwhile, we have provided several arguments pointing to PhIOAcBr ${ }^{35}$ being the active brominating species in our protocol.

Based on the experimental work presented here, and the known chemistry of I(III) reagents, ${ }^{36}$ we have compiled the following mechanic proposal (Scheme 5).

The mechanism starts with the coordination of the $\mathrm{AlBr}_{3}$ to PIDA in order to provide I. This generates the plausible active brominating species II and releases the aluminate $\mathbf{V}$, which is in equilibrium with IV. At this point, the corresponding phenolic molecule attacks to II, giving rise to III with the concomitant loss of the acetate anion and iodobenzene by reductive elimination. Finally, the spontaneous aromatization of III affords the desired brominated phenol derivative VI.

\section{Conclusions}

In summary, we have developed a new and efficient I(III)-based electrophilic bromination procedure for phenols, phenolethers and some heterocycles. Our protocol uses aluminium tribromide as ligand activator for the reaction and as a source of bromine atoms. The reaction is a reagent-economic procedure since its reagents PIDA and $\mathrm{AlBr}_{3}$ are inexpensive. The reagent is additionally easy to handle and the reactions proceed under very mild reaction conditions (r.t., open flask). Reagent activation is not necessary and excellent yields, mainly for naphthols, are observed. Our experimental and theoretical work suggests that PhIACOBr(II) is most likely the active brominating species, which can be prepared in situ or synthesized and isolated. This reagent is stable at least for one month, without losing its reactivity, if stored at $4{ }^{\circ} \mathrm{C}$. Our reagent shows excellent reactivity across a broad scope of functional groups in bis- and mono-annular phenols as well as heterocycles. Additionally, analgesics like naproxen or paracetamol were brominated with our procedure.

To the best of our knowledge this is the first report of the oxidation of the bromine atoms in $\mathrm{AlBr}_{3}$ to a " $\mathrm{Br}^{+}$" equivalent and their application to the bromination of phenolic cores. This 
strategy presents a clear advantage over those using peroxides, since it is not easy to control oxidation processes involving the latter reagents.

\section{Conflicts of interest}

There are no conflicts to declare.

\section{Acknowledgements}

We are grateful to CONACyT (CB-2013/220836) for financial support. We acknowledge the facilities of the DCNyE, the Chemistry Department, and the National Laboratory UGCONACyT (LACAPFEM) of the University of Guanajuato for full characterization. We thank CONACyT for fellowships to Y. S., P. D. N., V. R. and K. A. J. O. We also thank Dr Ramón Zapata for providing samples of Naproxen and Paracetamol and L. Yera for kind contribution.

\section{Notes and references}

1 Organic Bromine and Iodine Compounds, The Handbook of Environmental Chemistry, ed. Nelson A. H., Springer, Berlin, 2003, vol. 3R.

2 M. Tang and Z. Bao, Chem. Mater., 2011, 23, 446-455.

3 (a) C. Wagner, M. El Omari and G. M. König, J. Nat. Prod., 2009, 72, 540-543; (b) C. S. Neumann, D. G. Fujimori and C. T. Walsh, Chem. Biol., 2008, 15, 99-109; (c) K. Benkendroff, Mar. Drugs, 2013, 11, 1370-1398.

4 (a) G. W. Gribble, Chem. Soc. Rev., 1999, 28, 335-346; (b) For synthesis of 4-isocymobarbatol see: S. A. Snyder, D. S. Treitler and A. P. Brucks, J. Am. Chem. Soc., 2010, 132, 14303-14314; (c) For isolation of vidalol B see:N. Sitachitta and J. Gerwick, J. Nat. Prod., 1998, 61, 681-684; (d) For isolation of amathamide G see:H. Kang and W. Fenical, Tetrahedron Lett., 1997, 38, 941-944; (e) For total synthesis of $( \pm)$-chartelline C see:P. S. Baran, R. A. Shenvi and C. A. Mistos, Angew. Chem., Int. Ed., 2005, 44, 3714-3717; (f) P. S. Baran and R. A. Shenvi, J. Am. Chem. Soc., 2006, 128, 14028-14029; $(g)$ for gymnochrome A see:B. D. Morris and M. R. Prinsep, J. Org. Chem., 1998, 63, 9545-9547.

5 (a) M. Gobinath, N. Subramanian and V. Alagarsamy, J. Saudi Chem. Soc., 2015, 19, 282-286; (b) A. Jain, L. S. Duvvuri, S. Farah, N. Beyth, A. J. Domb and W. Khan, Adv. Healthcare Mater., 2014, 3, 1969-1985; (c) J. Wang, M. Sánchez-Roselló, J. L. Aceña, C. Del Pozo, A. E. Sorochinsky, S. Fustero, V. A. Soloshonok and H. Liu, Chem. Rev., 2014, 114, 2432-2506; (d) A. S. Christophersen, Toxicol. Lett., 2000, 127, 112-113; (e) For synthesis of JHU75575 see:S. R. Donohue, R. F. Dannals, C. Halldin and V. W. Pike, J. Med. Chem., 2011, 54, 2961-2970.

6 F. Hu, M. Patel, F. Luo, C. Flach, R. Mendelson, E. Garfunkel, H. He and M. Szostak, J. Am. Chem. Soc., 2015, 137, 1447314480.

7 N. Miyaura and A. Suzuki, Chem. Rev., 1995, 95, 2457-2483. 8 J. H. Li, Y. Liang and Y. X. Xie, Tetrahedron, 2005, 61, 72897293.
9 E. Negishi, Acc. Chem. Res., 1982, 15, 340-348.

10 C. B. Ziegler and R. F. Heck, J. Org. Chem., 1978, 34, 29412946.

11 R. Chinchilla and C. Nájera, Chem. Rev., 2007, 107, 874-922.

12 Q. Yu, L. Hu, Y. Wang, S. Zheng and J. Huang, Angew. Chem., Int. Ed., 2015, 54, 15284-15288.

13 (a) T. Zhang, X. Qi, S. Liu, R. Bai, C. Liu and Y. Lan, Chem.Eur. J., 2017, 23, 2690-2699; (b) P. Zhang, L. Hong, G. Li and R. Wang, Adv. Synth. Catal., 2015, 357, 345-349.

14 (a) F. Mendoza, R. Ruíz-guerrero, C. Hernández-Fuentes, P. Molina, M. Norzagaray-Campos and E. Reguere, Tetrahedron Lett., 2016, 57, 5644-5648; (b) S. M. Islam, R. A. Molla, A. S. Roy, K. Ghosh, N. Salam, M. A. Iqubal and K. Tuhina, J. Organomet. Chem., 2014, 761, 169-178.

15 (a) W. Liu, J. Chen, R. Jin, D. Xu, Y. Li, F. Ba, G. Gu, Y. Kuang and H. Guo, Org. Chem. Front., 2016, 3, 852-855; (b) X.-E. Li, W. Wu, X.-H. Fan and L.-M. Yang, RSC Adv., 2013, 3, 1209112095.

16 X. Sun, G. Shan, Y. Sun and Y. Rao, Angew. Chem., Int. Ed., 2013, 52, 4440-4444.

17 F. Mo, J. M. Yan, D. Qiu, F. Li, Y. Zhang and J. Wang, Angew. Chem., Int. Ed., 2010, 49, 2028-2032.

18 For NBS-organocatalyst see:Y. Xiong, F. Tan and Y.-Y. Yeung, Org. Lett., 2017, 19, 4243-4246.

19 (a) For NBS in ionic liquid, see:S. R. Pingali, M. Madhav and B. S. Jursic, Tetrahedron Lett., 2010, 51, 1383-1385; (b) For $\mathrm{Br}_{2}$ in ionic liquid, see:Y.-L. Ren, B. Wang, X.-E. Tian, S. Zhao and J. Wang, Tetrahedron Lett., 2010, 56, 6452-6455.

20 For NBS-TMSCl see:T. Mainbukaew, B. Thongsornkleeb, J. Tummatorn, A. Bunrit and S. Ruchirawat, Synlett, 2014, 25, 1769-1775.

21 For $\mathrm{Br}_{2}$-supercritical $\mathrm{CO}_{2}$ see:T. Delgado-Abad, M.-J. Ferrer, J. Reig-López, R. Mello, R. Acerete, G. Asensio and M. E. González-Núñez, RSC Adv., 2014, 4, 51016-51021.

22 For $\mathrm{Br}_{2}$ on $\mathrm{Fe}_{2} \mathrm{O}_{3}$-zeolites see:Y. Nishina and K. Takami, Green Chem., 2012, 14, 2380-2383.

23 D. Liang, X. Li, C. Wang, Q. Dong, B. Wang and H. Wang, Tetrahedron Lett., 2016, 57, 5390-5394.

24 A. Podgoršek, S. Stavber, M. Zupan and J. Iskra, Tetrahedron, 2009, 65, 4429-4439.

25 S. Song, X. Sun, X. Li, Y. Yuan and N. Jiao, Org. Lett., 2015, 17, 2886-2889.

26 J. Hou, Z. Li, X.-D. Xia and Z.-Q. Liu, Synth. Commun., 2014, 44, 181-187.

27 D. C. Braddock, G. Cansell and S. A. Hermitage, Synlett, 2004, 3, 461-464.

28 Z. Zhou and H. He, Synthesis, 2011, 2, 207-209.

29 P. A. Evans and T. A. Brandt, J. Org. Chem., 1997, 62, 53215326.

30 P. D. Nahide, V. Ramadoss, K. Juárez-Ornelas, Y. Satkar, R. Ortiz-Alvarado, J. M. J. Cervera-Villanueva, A. J. AlonsoCastro, J. R. Zapata-Morales, M. A. Ramírez-Morales, A. Ruiz-Padilla, M. A. Deveze-Álvarez and C. R. SolorioAlvarado, Eur. J. Org. Chem., 2018, 485-493.

31 (a) An extensive search in the literature reveals that this described route ( $O$-functionalization and bromination) is opposite that most commonly used for the synthesis of 29- 
32. This supports the excellent reactivity and the good tolerance to bulky functional groups of our developed bromination procedure; ; $(b)$ The latent $\alpha$-bromination in acetyl derivative, as well as the benzylic bromination in benzyl derivative or bromination in triple bond for propargyl example was not observed; this also showed the chemoselectivity of our procedure.

32 Excellent examples of reagents that induce halocyclization:

(a) For $\mathrm{Et}_{2} \mathrm{SBr} \cdot \mathrm{SbCl}_{5} \mathrm{Br}: \mathrm{S}$. A. Snyder and D. S. Treitler, Angew. Chem., Int. Ed., 2009, 121, 8039-8043; (b) For CDSC, IDSI and BDSB: S. A. Snyder, D. S. Treitler and A. P. Brucks, J. Am. Chem. Soc., 2010, 132, 14303-14314.

33 See $\mathrm{ESI} \dagger$ for a detailed preparation procedure.

34 M. J. Frisch, G. W. Trucks, H. B. Schlegel, G. E. Scuseria, M. A. Robb, J. R. Cheeseman, G. Scalmani, V. Barone, G. A. Petersson, H. Nakatsuji, X. Li, M. Caricato, A. V. Marenich, J. Bloino, B. G. Janesko, R. Gomperts, B. Mennucci, H. P. Hratchian, J. V. Ortiz, A. F. Izmaylov, J. L. Sonnenberg, D. Williams-Young, F. Ding, F. Lipparini, F. Egidi, J. Goings, B. Peng, A. Petrone, T. Henderson, D. Ranasinghe, V. G. Zakrzewski, J. Gao, N. Rega, G. Zheng, W. Liang, M.
Hada, M. Ehara, K. Toyota, R. Fukuda, J. Hasegawa, M. Ishida, T. Nakajima, Y. Honda, O. Kitao, H. Nakai, T. Vreven, K. Throssell, J. A. Montgomery Jr, J. E. Peralta, F. Ogliaro, M. J. Bearpark, J. J. Heyd, E. N. Brothers, K. N. Kudin, V. N. Staroverov, T. A. Keith, R. Kobayashi, J. Normand, K. Raghavachari, A. P. Rendell, J. C. Burant, S. S. Iyengar, J. Tomasi, M. Cossi, J. M. Millam, M. Klene, C. Adamo, R. Cammi, J. W. Ochterski, R. L. Martin, K. Morokuma, O. Farkas, J. B. Foresman and D. J. Fox, Gaussian 16, Revision A.03, Gaussian, Inc., Wallingford CT, 2016, see ESI $\dagger$ for further details.

35 PhIOAcBr has been previously postulated as a I(III)-based brominating active species, see ref. 26. However, in this reference, there is a very narrow scope and there is no evidence to support its formation, stability, reactivity or physicochemical characteristics.

36 (a) V. Zhdankin, ARKIVOC, 2009, i, 1-62; (b) V. Zhdankin and P. J. Stang, Chem. Rev., 2002, 102, 2523-2584.

37 P. Espinet and A. M. Echavarren, Angew. Chem., Int. Ed.Angew. Chem., Int. Ed., 2004, 43, 4707-4734. 